\title{
COMMENT
}

https://doi.org/10.1057/s41599-019-0322-x

\section{The public's health and the social meaning of guns}

\author{
Sandro Galea ${ }^{1 \star} \&$ Salma M. Abdalla (i) ${ }^{1}$
}

\begin{abstract}
Guns have long affected the health of the American population. The preponderance of evidence showing that guns harm the public's health suggests that regulating civilian access to guns should be universally embraced. Yet, action on guns has been vanishingly small. Why? At core, the inaction reflects a clash between our knowledge and our values. Despite the compelling public health argument for better gun control, we have not been able to grapple with the social meaning of guns, which informs the values that shape the public conversation. Doing so will require public health to engage in transdisciplinary work that pushes the field's boundaries.
\end{abstract}




\section{A public health approach to guns}

W hy do guns continue to cause as much death and disability in the United States as they currently do? This special issue on the social meaning of guns includes papers that grapple with the meaning that guns have taken on, and how that meaning, perhaps larger than the object itself, has come to dominate the gun debate in the US (Metzl, 2019a, b). This comment considers how public health has perhaps fallen short in understanding the social meaning of guns and the implications it has for the role of public health in tackling gun violence in the country.

Public health's role starts with the consequences of guns themselves. More Americans die from guns than from motor vehicle accidents and have done so for several years now, especially as deaths from the latter have been declining and death from guns have been on the rise. Further, for every American who dies from a gunshot, there are 2-3 times more people who are injured by a gun. Firearm injuries are in turn associated with protracted recovery periods and a long-tail burden of mental and physical health consequences (Kalesan et al., 2019; Rowhani-Rahbar et al., 2019). Data on the mental health consequences of guns remain hard to come by. Available evidence, however, suggests that those who are shot and survive, their families, and their communities are likely to have a high prevalence of mental disorders that are disabling in the long term. This burden of death and disability occurs on a backdrop of the high prevalence of gun ownership in the United States. Americans are about $4 \%$ of the world's population, but they own nearly half of the world's handguns-the gun type that is associated with the overwhelming majority of gun deaths and injuries.

The science of firearms and health remains substantially underfunded compared to the burden of disease (Stark and Shah, 2017). Yet, we know enough to know that the high prevalence of guns is the primary driver of gun-related death and disability and that having fewer guns would undoubtedly result in fewer such adverse consequences. By way of example drawn from natural experiments, when Connecticut passed a 1995 law requiring background checks to obtain gun permits, gun homicide dropped by about $40 \%$ and gun suicide dropped by about $15 \%$. Conversely, when Missouri, in 2007, repealed gun licensing requirements, gun homicide and suicide increased by $25 \%$ and $16 \%$, respectively (Kristof, 2017; Metzl, 2019a, b).

\section{Public health and gun culture}

The United States therefore faces a gun violence epidemic that, in theory, should be largely avoidable. This has been well articulated in the past decade and represents the cornerstone on which the public health approach to gun violence has, predominantly, since rested (Hemenway and Miller, 2013). Yet, the challenge of guns and gun-related violence remains intractable in the country (Galea, 2019). It is true that a series of high-profile mass shootings-particularly ones in Newtown, Connecticut, Las Vegas, Nevada, and Parkland, Florida-have, episodically, galvanized efforts toward gun safety reforms, particularly in the Democratic party. However, meaningful legislative change that can influence the gun violence epidemic remains elusive, despite public health's best efforts.

Why have we then not seen more effort to come to terms with an issue of profound public health consequence? The intransigence on this issue can in part be attributed to the overwhelming power of commercial interests who have invested millions of dollars in maintaining a profitable status quo. The issue, however, has more complex roots than just commercial interests. It is clear that the social role of guns in American life has created support for the continued widespread availability of guns. The social meaning of guns is a construction that shapes values and expectations, informs and inflects the public conversation, and sets the bounds within which any conversation around gun safety reform can take place.

This has important implications for how public health engages with this issue. If public health evidence suggests that we should be moving toward fewer guns, but we are collectively far from doing so, it behooves public health to ask: why does what we know not become action? And, as a corollary, how does public health grapple with a deeper social meaning of guns that challenges the potential course of action to which the science points?

\section{At the intersection of knowledge and values}

An understanding of these questions is perhaps best grounded in a first-principles approach to the intersection between knowledge and values, asking the fundamental question: what does it really mean to "know" something? (Galea, 2017) Public health is fundamentally a data-driven science, confident in its approach that sufficient data will ultimately illuminate what the causes of health are so that we intervene to maximize health. To say that we "know" something, within the context of public health therefore, emerges from the work of many, through iterative research, writing, and debate. The scientific method and the rigor of peer review exist to provide a framework for this work of justification. Our tradition of discussion and argument allows population health scholars to further refine what we know. This process is, by design, neither easy nor quick. Yet, for us to call "knowledge" what may have started as an idea, a hunch, means we must engage with each step along the road from supposition, to proof, to, ultimately, consensus around a given issue.

Values, however, complicate what we know and what we do about what we know and push the bounds of what public health is comfortable tackling. Values push us to ask the question: what do we mean when we say we care about something? Values are what we choose to focus on, in a world of limited time and resources. This choice is both necessary-if we are to get anything done-and deeply revealing. Values are defined by their relationship to what we do, and strong arguments have previously been presented on the role of consequentialism in informing population health science (Galea, 2013). A consequentialist approach to public health reflects a fundamental truth about values - they tend to catalyze action. When we genuinely care about something, particularly when it is an injustice in need of correcting or a matter of lives to be saved, it is difficult to remain a spectator or to limit our activities to the accumulation of knowledge for its own sake. Our values push us to mobilize our knowledge in pursuit of healthier populations, guiding our priorities toward the areas where we can best make a difference. This becomes particularly relevant in public health in cases where societal values may not be aligned with what the science suggests improves health. In this case, including, perhaps in the context of guns, the clash between our values-as embedded within gun culture-and what the science suggests-that we need to have fewer guns-becomes a barrier to action.

\section{Where public health falls short}

It is this clash between knowledge and values that ultimately represents the gap in public health's work on guns. It is a limitation that is perhaps most responsible for a wholesale national inaction on guns despite robust and ever-growing public health evidence of the health consequences of guns.

How can public health then be informed by this limitationand move forward-through an understanding of the confluence of knowledge and values? When knowledge and values align, as is the case, for example, with polio eradication, the work of public health becomes relatively straightforward: we know what to do and we care about doing it, leaving only technical questions about 
how we can achieve our stated ends through the best possible means. Matters get much harder when knowledge and values do not align, as is the case with guns. While the argument for doing something about guns, from a public health perspective, is overwhelming and incontrovertible, national values are far from aligned with this public health goal. For example, to many Americans, gun ownership is considered a right, not a privilege that can be regulated. These values create an impasse, one where knowing is not enough, and where tangling with the fundamental meaning of guns that challenges knowledge must be a core function of any public health approach to gun violence.

This mismatch makes a strong case for public health to engage in questions about the social meaning of guns, thus pushing the science of population health to better understand how guns are valued and the role they play in cultural and civic life.

There are some early indications that public health is coming to terms with this perspective. A "Call to action" around guns issued by the Association of Schools and Programs of Public Health-the largest professional association of academic public health in the world-noted that "there is a specific imperative for innovative approaches developed at the local community level that allow for effective communication about the issues in compelling language" (Branas et al., 2017). This call to action opens the door to grappling with the complex narratives around guns that underpin the gun debate in the country. A small body of public health literature has emerged that aims to quantify the contribution of "gun culture" to the gun violence epidemic. One analysis, for example, showed that being a part of a "social gun culture" was associated with 2.25 times greater likelihood of gun ownership (Kalesan et al., 2016). In that study, "social gun culture" was assessed using four questions that examined whether an individual's "social circle thinks less of them if they did not own a gun," "family thinks less of them not owning a gun," "social life with family involves guns," and "social life with friends involves guns." This work serves as the start of a conversation about the social meaning of guns and how it may play into the persistent presence of guns in American life, contributing to a public health crisis that, at face value, should be preventable.

Yet, to the extent that this remains a relatively new issue in public health, it suggests that public health has much work to do. In the defense of public health, grappling with the social meaning of guns requires a transdisciplinary approach that substantially pushes the field outside of its typical disciplinary comfort zone. While academic public health readily and often speaks about a kinship with fields such as anthropology, sociology, history, and the humanities, in truth, these areas are relatively marginal to the mainstream of population health science and public health practice. However, the disciplinary perspectives that these areas offer represent an essential component of public health's coming to terms with the social meaning of guns, how it informs values, and how those values intersect with what we know. The field of sociology, for example, is equipped with research tools and theoretical methods that can be utilized by public health scholars to grapple with the concept of social values and how they apply to the gun culture in the United States. Sociology can help us understand how social values function to sustain group identities over time and why some values are more intractable than others. It can also help us think reflectively about the intersection between our own values as public health scholars and those of the people and groups we study (Carlson, 2015; Yamane, 2017; Whitehead et al., 2018). Public health can also benefit from social-historical scholarship that provide an understanding of the complex relationship between racial oppression and guns, gun violence, and gun control (Johnson, 2014; Dunbar-Ortiz, 2018). Knowledge from these studies will help public health scholars understand the social roots that fuel the national debate around guns in this country. Taking a multi-disciplinary approach will push toward action that can mitigate the consequences of guns and gun violence.

\section{Conclusion}

The fact that the social meaning of guns has evaded public health for so long reflects the disciplinary limitations of the fieldsimply put, public health has not historically been particularly adept at understanding culture and symbols that inform the dominant narrative. Fundamentally, the business of public health is saving lives and improving health. But what does public health do when lives seemingly do not wish to be saved? Guns represent an important case for public health thought and action. As firearm research accumulates, fueled by a recent rise in gun-research funding, we run the risk of furthering an imbalance between knowledge and values-knowing ever more how we may best, in theory, mitigate the consequences of guns, while failing to understand how the social meaning of guns shapes values that effectively limit any effort to act on this knowledge. This reality strongly calls for a public health approach to gun violence that makes understanding the social meaning of guns one of its core functions. To do so will require work across disciplines and imaginative scholarship to the end of finding the intersection of knowledge and values that can promote the public's health.

Received: 28 June 2019; Accepted: 10 September 2019;

Published online: 01 October 2019

\section{References}

Branas CC et al. (2017) Academic public health and the firearm crisis: an agenda for action. Am J Public Health 107(3):365-367. https://doi.org/10.2105/ AJPH.2016.303619.

Carlson J (2015) Citizen-protectors: the everyday politics of guns in an age of decline. Oxford University Press: Oxford.

Dunbar-Ortiz R (2018) Loaded: a disarming history of the Second Amendment. City Lights Publishers, San Francisco.

Galea S (2013) An argument for a consequentialist epidemiology. Am J Epidemiol 178(8):1185-1191. https://doi.org/10.1093/aje/kwt172.

Galea S (2017) Knowledge and values. In Healthier: fifty thoughts on the foundations of population health. Oxford Press, Oxford, p 273. https://global.oup. com/academic/product/healthier-9780190662417?cc=us\&lang=en\&. Accessed 27 June 2019.

Galea S (2019) Making the case for a world without guns. Lancet Public Health 4 (6):e266-e267. https://doi.org/10.1016/S2468-2667(19)30021-0.

Hemenway D, Miller M (2013) Public health approach to the prevention of gun violence. New Engl J Med 368(21):2033-2035. https://doi.org/10.1056/ NEJMsb1302631.

Johnson N (2014) Negroes and the gun: the Black tradition of arms. Prometheus Books, Amherst, NY.

Kalesan B et al. (2016) Gun ownership and social gun culture. Inj Prev 22 (3):216-20. https://doi.org/10.1136/injuryprev-2015-041586.

Kalesan B et al. (2019) Risk of 90-day readmission in patients after firearm injury hospitalization: a nationally representative retrospective cohort study. J Inj Violence Res 11(1):65-80. https://doi.org/10.5249/jivr.v11i1.979.

Kristof N (2017) How to reduce shootings. The New York Times. https://www. nytimes.com/interactive/2017/11/06/opinion/how-to-reduce-shootings.html. Accessed 28 Jun 2019.

Metzl JM (2019a) Dying of whiteness: how the politics of racial resentment is killing America's heartland. Hachette Book Group, New York, NY. https:// www.basicbooks.com/titles/jonathan-m-metzl/dying-of-whiteness/ 9781541644960/. Accessed 28 Jun 2019.

Metzl JM (2019b) What guns mean: the symbolic lives of firearms. Palgrave Commun 5(1):35. https://doi.org/10.1057/s41599-019-0240-y.

Rowhani-Rahbar A, Zatzick DF, Rivara FP (2019) Long-lasting consequences of gun violence and mass shootings. JAMA 321(18):1765. https://doi.org/ 10.1001/jama.2019.5063.

Stark DE, Shah NH (2017) Funding and publication of research on gun violence and other leading causes of death. JAMA 317(1):84. https://doi.org/10.1001/ jama.2016.16215.

Whitehead AL, Schnabel L, Perry SL (2018) Gun control in the crosshairs: Christian nationalism and opposition to stricter gun laws. Socius Sociological Res Dyn World. https://doi.org/10.1177/2378023118790189. 
Yamane D (2017) The sociology of U.S. gun culture. https://doi.org/10.1111/ soc4.12497.

\section{Competing interests}

The authors declare no competing interests.

\section{Additional information}

Correspondence and requests for materials should be addressed to S.G.

Reprints and permission information is available online at http://www.nature.com/ reprints

Publisher's note Springer Nature remains neutral with regard to jurisdictional claims in published maps and institutional affiliations. (c) (i) Open Access This article is licensed under a Creative Commons Attribution 4.0 International License, which permits use, sharing, adaptation, distribution and reproduction in any medium or format, as long as you give appropriate credit to the original author(s) and the source, provide a link to the Creative Commons license, and indicate if changes were made. The images or other third party material in this article are included in the article's Creative Commons license, unless indicated otherwise in a credit line to the material. If material is not included in the article's Creative Commons license and your intended use is not permitted by statutory regulation or exceeds the permitted use, you will need to obtain permission directly from the copyright holder. To view a copy of this license, visit http://creativecommons.org/ licenses/by/4.0/.

(C) The Author(s) 2019 